\title{
Assessing the organisational and individual strengths use and deficit improvement amongst sport coaches
}

\begin{tabular}{|c|c|}
\hline \multicolumn{2}{|c|}{$\begin{array}{l}\text { Authors: } \\
\text { Frederick W. Stander }{ }^{1} \\
\text { Karina Mostert }^{1}\end{array}$} \\
\hline \multicolumn{2}{|c|}{$\begin{array}{l}{ }^{1} \text { WorkWell Research Unit for } \\
\text { Economic and Management } \\
\text { Sciences, North-West } \\
\text { University, South Africa }\end{array}$} \\
\hline \multicolumn{2}{|c|}{$\begin{array}{l}\text { Correspondence to: } \\
\text { Karina Mostert }\end{array}$} \\
\hline \multicolumn{2}{|c|}{$\begin{array}{l}\text { Email: } \\
\text { karina.mostert@nwu.ac.za }\end{array}$} \\
\hline \multicolumn{2}{|c|}{$\begin{array}{l}\text { Postal address: } \\
\text { Private Bag X6001, Box } \\
\text { Potchefstroom 2520, } \\
\text { South Africa }\end{array}$} \\
\hline \multicolumn{2}{|c|}{$\begin{array}{l}\text { Dates: } \\
\text { Received: } 10 \text { June } 2013 \\
\text { Accepted: } 22 \text { July } 2013 \\
\text { Published: } 01 \text { Nov. } 2013\end{array}$} \\
\hline \multicolumn{2}{|c|}{$\begin{array}{l}\text { How to cite this article: } \\
\text { Stander, F.W.S., \& Mostert, } \\
\text { K. (2013). Assessing the } \\
\text { organisational and individual } \\
\text { strengths use and deficit } \\
\text { improvement amongst } \\
\text { sport coaches. SA Journal } \\
\text { of Industrial Psychology/SA } \\
\text { Tydskrif vir Bedryfsielkunde, } \\
\text { 39(2), Art. \#1160, } 13 \text { pages. } \\
\text { http://dx.doi.org/10.4102/ } \\
\text { sajip.v39i2.1160 }\end{array}$} \\
\hline \multicolumn{2}{|c|}{$\begin{array}{l}\text { Copyright: } \\
\text { (C) 2013. The Authors. } \\
\text { Licensee: AOSIS } \\
\text { OpenJournals. This work } \\
\text { is licensed under the } \\
\text { Creative Commons } \\
\text { Attribution License. }\end{array}$} \\
\hline \multicolumn{2}{|l|}{ Read online: } \\
\hline 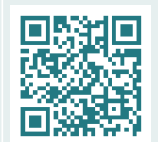 & $\begin{array}{l}\text { Scan this QR } \\
\text { code with your } \\
\text { smart phone or } \\
\text { mobile device } \\
\text { to read online. }\end{array}$ \\
\hline
\end{tabular}

Orientation: The orientation of this study is towards strengths use and deficit improvement and the relationship with engagement.

Research purpose: To (1) determine whether adapted versions of the Strengths Use and Deficit Improvement Questionnaire (SUDIQ) and Utrecht Work Engagement Scale (UWES) are valid and reliable, (2) determine the relationship of the SUDIQ dimensions in the nomological net, and (3) test a structural model.

Motivation for the study: To gain a better understanding of the outcomes of following a balanced approach within a sport coaching context.

Research design, approach and method: A cross-sectional research approach was used. An availability sample $(N=364)$ of teachers occupying roles as sport coaches from various schools across three provinces in South Africa was used. Structural equation modelling was used to test the factor structures and the structural model.

Main findings: The results indicated a valid factor structure for the adapted SUDIQ and UWES. Relationships between the SUDIQ dimensions and job and personal resources were positive and significant. Individual strengths use was the strongest predictor of engagement. Individual deficit improvement and organisational strengths use were also significant predictors. Organisational deficit improvement did not significantly predict engagement.

Practical/managerial implications: Evidence suggests the adapted SUDIQ and UWES can be utilised effectively in a sport coaching environment. Organisational strengths use is also important in managing engagement levels of sport coaches.

Contribution/value-add: Valid and reliable measures were provided for use in a sport coaching environment. It substantiates the outcomes that can be gained by following a combined approach based on strength and deficit.

\section{Introduction}

In traditional organisational and people development approaches, the majority of organisations have focused their attention towards the improvement of employee deficits. These organisations have sought to secure insight into the so-called flaws and weak points of their people, as a means of identifying areas of insufficiency that need to be redressed and rectified (Buckingham \& Clifton, 2001). The training and development functions of major corporations have long been sanctioned to design and convene intercessions to resolve areas of development identified in the organisation as a means of ensuring greater levels of performance and growth (Clifton \& Harter, 2003). From an organisational perspective, this approach has come to be known as the deficit-based approach (DBA) and it has served assiduously in addressing key areas of shortage within organisations and individuals as a means of attaining goals and facilitating growth. Linley and Harrington (2006) have remarked that it is ultimately essential to be realistic about the shortcomings of an individual or organisation and to address these shortcomings in order to move towards a more favourable or desired state.

Although the DBA has long served organisational and individual development, a modern perspective has emerged that promotes the idea of a more balanced predilection on which the strengths and potential of human beings are also focused (Linley, Joseph, Harrington \& Wood, 2006; Seligman \& Csikszentmihalyi, 2000; Wood, Linley, Maltby, Kashdan \& Hurling, 2011). Known as the strength-based approach (SBA), this predilection has the aim of accentuation of talents and virtues of people (Buckingham \& Clifton, 2001). Strengths can be described as positive personality traits, inimitable to every person (Seligman, 2002). Peterson and Seligman (2004) have described the SBA as an exertion towards sustainable well-being through the identification and execution of human being character strengths and qualities. The SBA is a key enabler of optimal human functioning (Kaiser \& White, 2009). This approach is very much in line 
with the modern field of positive psychology, a movement that has championed for recognition and development of positive emotions, traits and characteristics, as opposed to the traditional psychology focus that so rigorously sought to rectify human abnormality, deficiency and flaws (Cravens, Oliver \& Stewart, 2010).

Both the DBA and SBA have been associated with positive outcomes. For example, Linley and Harrington (2006) have established that the absence of a DBA will render an organisation unable to move towards a more desirable state and to achieve organisational goals. In the case of SBA, Wood et al. (2011) have found optimal development possible only when human potential and strengths are also part of the equation. Bouskila-Yam and Kluger (2011) describe a positive relationship between adopting a SBA and organisational motivation and job performance, whilst Sienstra (2010) has indicated that a positive relationship exists between following an SBA and task performance amongst employees.

The importance of achieving high levels of task performance has long been part of the sport coaching profession, a trade that is characterised by severe levels of pressure and demands (Olusuga, Maynard, Hays \& Butt, 2012). For the sport coach to be successful, they must be trained and developed to fulfil multiple roles (Lyle, 2002). This calls for an approach of totalised development, focused on the coach's strengths and areas of deficit, in order for optimum functioning to become possible (Wood et al., 2011). To be successful in the demanding and stressful environment of sport coaching (Gould, Guinan, Greenleaf \& Chung, 2002), a balanced strength-based and deficit-based development approach can be very useful.

In general, little empirical work has been done with regard to measuring the extent of both strengths use and deficit improvement, from an organisational or an individual perspective. The critical need for providing such measures has been addressed by Els, Mostert, Van Woerkom, Rothmann and Bakker (in press), who have designed the Strengths Use and Deficit Improvement Questionnaire (SUDIQ) as a measure that can assess the extent of organisational strengths use (OSU), organisational deficit improvement (ODI), individual strengths use (ISU) and individual deficit improvement (IDI). In this study, this scale will be extended in an adapted version to the sport sector, an industry that will benefit largely from extended empirical work (Levermore \& Beacom, 2009). It will be supplemented by an adapted version of the Utrecht Work Engagement Scale (UWES) to provide two adapted measures that can validly and reliably measure well-being-related constructs in the sport sector. This will hold significant practical value, particularly in the South African context, where sport has throughout history played a significant role as social catalyst in uniting segregated communities and transforming the country (Keim, 2003; Swart, Bob, Knot \& Salie, 2011).

As is the case with regard to empirical work in measuring the extent of a balanced approach (i.e. including both strengths and deficits), both from an organisational and from a personal perspective, limited work has thus far investigated structural paths in facilitating desired outcomes. In this study, the strength and deficit approaches' potential role in creating work engagement will be explored. These structural paths will be investigated in the context of a sport environment, and more specifically the context of sport coaching.

The objectives of this study are therefore: (1) to test the factorial validity and reliability of the adapted versions of the SUDIQ and the UWES in the sport coaching environment, (2) to investigate the relationship of the four SUDIQ dimensions in the nomological net (including job and personal resources and work engagement), and (3) to test a structural model with the four SUDIQ dimensions predicting work engagement.

\section{Literature review}

\section{Organisational strengths use and organisational deficit improvement as job resources}

The Job Demands-Resources (JD-R) model is a theoretical model describing that every job has its own unique set of risk and resource factors that play a major role in job-related stress (Bakker \& Demerouti, 2007; Bakker, Demerouti, Taris, Schaufeli \& Schreurs, 2003). Demerouti and Bakker (2011) have classified these factors into two broad categories: job demands and job resources. Job demands are those psychological, social, organisational or physical strains associated with a specific job role that requires a sustained emotional or cognitive effort and is associated in some manner with psychological cost (Bakker \& Demerouti, 2007). Job resources include those occupational resources that facilitate the attainment of organisational outcomes and goals (Bakker \& Demerouti, 2007). Job resources can manifest in various dimensions, including physical, social or organisational resources (Bakker \& Demerouti, 2008; Xanthopoulou, Bakker, Demerouti \& Schaufeli, 2009). Job resources constitute those capitals that stimulate advancement towards reaching workplace goals, condense job demands and related physiological and psychological costs, and harness advancement and growth across various individual and organisational levels (Xanthopoulou et al., 2009). Job resources also enable aspects such as motivation, well-being and work engagement amongst employees (Hakanen, Perhoniemi \& Toppinen-Tanner, 2008). The JD-R model can be adapted and applied to various job roles, industries and occupations (Demerouti \& Bakker, 2011).

Organisational strengths use refers to the employees' perception of the extent to which the practices, policies and procedures of a specific organisation allow for the utilisation of their areas of strength (Els et al., in press). On the other hand, organisational deficit improvement can be described as employees' perception of the extent to which a specific organisation will provide for structures, programmes and policies to improve said employees' areas of deficit or flaw (Els et al., in press).

Organisational strengths use can be conceptualised as a job resource because it facilitates extrinsic motivation amongst 
employees and creates a climate in which individuals will invest their full effort and available capacity to ensure accomplishment of the work task (Demerouti \& Bakker, 2011; Els et al., in press). Organisational strengths use has been proven valuable to create several positive work-related outcomes, such as higher work engagement (Harter, Hayes \& Schmidt, 2002), reduced employee turnover (Clifton \& Harter, 2003; Stefanyszyn, 2007), and increased job satisfaction (Peterson, Stephens, Park, Lee \& Seligman, 2009). Bouskila-Yam and Kluger (2011) established a correlation between organisational strengths use and increased levels of job performance and motivation of employees. In two separate studies, Cameron, Mora, Leutscher and Calarco (2011) have found the result of organisational strengths use to be higher levels of productivity and profitability.

Organisational deficit improvement has been particularly evident in the training and development functions of organisations, where the identification of employees' areas of flaw has formed the basis of the company's training needs (Arthur, Bennett, Edens \& Bell, 2003). Brown (2002) has argued that organisational deficit improvement is aimed at bridging the gap between incapacity to perform and enhanced skills and capabilities to ensure the organisation reaches its goals. Linley, Woolston and Biswas-Diener (2009) mention that by not sufficiently addressing areas of insufficiency or deficit in an organisation, these deficiencies can lead to learned behaviours that are very difficult to alter and derail the organisation's effort to reach desired objectives. This sentiment is shared by Linley and Harrington (2006), who describe the rectification of flaws as central in moving the organisation from one point towards a more desirable state. To enhance organisational performance and stimulate growth, areas of deficit must be a central focus in the training and development interventions designed by organisations (Clifton \& Harter, 2003).

Clearly, both organisational strengths use and deficit improvement are important factors in reaching organisational goals, mitigating demands in the workplace and stimulating employee development and growth: the prerequisite criteria for job resources (Xanthopoulou et al., 2009). They are therefore classified as job resources in the context of this study.

\section{Individual strengths use and individual deficit improvement as personal resources}

The JD-R model recently expanded to include personal resources as part of its compilation of job resources (Xanthopoulou et al., 2009). There is a wide definition of personal resources; they have been described as: 'aspects of the self that are generally linked to resiliency' (Hobfoll, Johnson, Ennis \& Jackson, 2003, p. 632). Clearly, the connotation of 'personal' is an individual characteristic (Hobfoll, 1989). The individual implication considered, personal resources are, however, still relevant to the working environment (Van den Heuvel, Demerouti, Schaufeli \& Bakker, 2010) and can therefore be described as those aspects that assist individuals in dealing with challenges and stressors within their particular working environment (Pearlin \& Schooler, 1978). They prove useful in dealing with adverse situations and creating more favourable circumstances for the attainment of personal goals (Van den Heuvel et al., 2010).

From the perspective of individual strengths use and deficit improvement, two dimensions must be distinguished. Individual strengths use is defined as the individual's selfstarting behaviour to use their strengths, potential and virtues in the workplace, whilst individual deficit improvement describes the individual's self-starting behaviour towards improving areas of deficit, weakness or flaw (Els et al., in press). Both individual strengths use and individual deficit improvement could greatly serve as personal resources, as they can be utilised towards holistic development of the self (Kaiser \& White, 2009), as well as towards the fostering of high levels of subjective well-being (Govindji \& Linley, 2007), making personal and work-related goals more attainable. Individual strengths use and individual deficit improvement will provide a person with greater control over the demands and challenges associated with their job, equipping that person to achieve their work-related objectives. Therefore, individual strengths use and deficit improvement could be classified as personal resources.

\section{Development and validation of the Strengths Use and Deficit Improvement Questionnaire}

The evidently positive impact of strength usage on subjective well-being and organisational attainment of goals has led to various strength identification instruments being developed, including the 'Values in Action' (VIA) (Peterson \& Seligman, 2004), the Clifton StrengthFinder 2.0 (Rath, 2002) and the Realise 2 (Linley, Willars \& Biswas-Diener, 2010). Although these instruments prove valuable in assessing and identifying human strengths, little empirical work exists on what has been described by Clifton and Harter (2003) as the process movement towards creation of self-awareness and actual utilisation of strengths. It must be possible to assess the actual extent to which organisations and individuals use their strengths. Moreover, the availability of measures that balance this with the assessment of the extent to which organisations and individuals can improve deficits proves a further important priority.

No measures exist that could assess the extent to which organisations and individuals use strengths and improve deficits. This represents a major need as it has been proven that both strengths use and deficit improvement, from an organisational and an individual perspective, can create favourable outcomes and act as resources to achieve workrelated goals (Els et al., in press). Some effort in this direction has been led by the Dutch scale developed by Van Woerkom that drew from the Strength Knowledge Scale (Govindji \& Linley, 2007), the Gallup Workplace Audit (Harter, Hayes \& Schmidt, 2002), and the Strengths use Scale (Govindji \& Linley, 2007). A major priority in empirical science, however, remains the ability to measure the extent to which organisations develop employees' strengths as well as the 
individual's internal ability to develop and capitalise on strengths, on the one hand, but also to measure the extent to which organisations and individuals have capacity for the improvement of deficits.

This research gap has been addressed by Els et al. (in press) through the development of a scale that assesses the degree to which individuals experience the utilisation of their talents and strengths, not only by the organisation in which they function, but also on individual level. Furthermore, the scale developed also provides for the assessment of perceived levels of improvement of deficits, on an organisational and an individual level. This is fundamentally important, as it enables what Peterson and Seligman (2004) describe as optimum development by addressing areas of both strength and deficit in a balanced approach.

The scale, known as the SUDIQ, was developed through a rigorous process, including construct conceptualisation based on the JD-R model of job and personal resources, item generation and evaluation, item development, item refinement and item judgement. The four factors of the questionnaire were extracted through a scree plot and eigen values in an exploratory factor analysis during the pilot study $(N=241)$. A four-factor structure was confirmed with confirmatory factor analysis in a sample of 699 employees in a variety of organisational settings (Els et al., in press). The four-factor structure comprised organisational strengths use, organisational deficit improvement, individual strengths use and individual deficit improvement. Very good reliability has been reported by Els et al. (in press), pertaining to the four factors, through Cronbach's alpha coefficients. These include organisational strengths use $(\alpha=0.96)$, organisational deficit improvement $(\alpha=0.93)$, individual strengths use ( $\alpha=$ $0.94)$ and individual deficit improvement $(\alpha=0.94)$.

For the purpose of this study, an adapted version of the SUDIQ was used to make it specific to the sport coaching context. The hypothesis is that the adapted SUDIQ will hold a valid four-factor structure, as was proven in the research of Els et al. (in press). These factors will include organisational strengths use, organisational deficit improvement, individual strengths use and individual deficit improvement (Hypothesis 1a). Following this, it is predicted that all four dimensions will be reliable (Hypothesis 1b). These results will render the adapted SUDIQ an instrument that can be used in the sport coaching domain with high levels of scientific integrity.

\section{Work engagement}

Work engagement has been defined by Schaufeli and Bakker (2004, p. 295) as a: 'positive, fulfilling, work-related state of mind, characterised by vigour, dedication, and absorption'. Vigour can be witnessed in displays of on-going positive affections for elements and dimensions in one's work context, being visible in cognitive vivacity, physical power and emotional force (Schaufeli, Salanova, González-Romá \& Bakker, 2002). Inspiration and pride for one's job constitute dedication (Schaufeli et al., 2002). Absorption is theorised as being happily engrossed in one's work and struggling to detach oneself from it (Schaufeli \& Bakker, 2004; Schaufeli et al., 2002). Recently, several studies only include the 'core dimensions' of engagement, namely vigour and dedication. This is mainly because absorption has recently been conceptualised as a consistent state of 'flow' (Csikszentmihalyi \& Rathunde, 1993) that emerges as a result or consequence of work engagement, rather than a factor thereof (Montgomery, Peeters, Schaufeli, \& Den Ouden, 2003). It is also seen as a less central component of work engagement (Schaufeli \& Bakker, 2001). Based on these arguments, only vigour and dedication, the 'core' dimensions of engagement will be included in this study. Schutte, Toppinen, Kalimo and Schaufeli (2000) have described engagement as a crucial stimulator of work performance, confidence and effectiveness within the work domain. Work engagement leads to higher levels of commitment (Demerouti, Bakker, De Jonge, Janssen \& Schaufeli, 2001) and has been a predictor of higher motivation to learn amongst employees (Sonnentag, 2003). It is clearly a sought-after construct in any organisational setting.

Work engagement is measured using the UWES, a 17item instrument that assesses the three factors of vigour, dedication and absorption (Schaufeli et al., 2002). Cronbach's alpha coefficients for the measure have varied between 0.78 and 0.89 (Schaufeli et al., 2002). Various factor structures for the UWES have been established, including the traditional three-factor structure (Schaufeli \& Bakker, 2004), a two-factor structure consisting of vigour and dedication (Demerouti, Mostert \& Bakker, 2010; Mostert, Cronje \& Pienaar, 2006), as well as a one-factor structure. Recent studies have favoured the two-factor conceptualisation of work engagement (Montgomery et al., 2003; Schaufeli \& Bakker, 2001). The reliability of the two factor model has been shown to be sufficient, with Cronbach's alpha values of 0.73 for vigour and 0.85 for dedication (Mostert, Peeters \& Rost, 2011). This was also proven in a study by Mostert et al. (2006), who established Cronbach's alpha values of 0.74 for vigour and 0.84 for dedication.

For the purposes of this study, an adapted version of the UWES was utilised to ensure that the measure was specific for the sport coaching context. Although the measure was adapted, the hypothesis holds that the UWES will have a valid two-factor structure (consisting of vigour and dedication), based on the theoretical underpinnings of the instrument and previous findings (Montgomery et al., 2003; Mostert et al., 2011; Schaufeli \& Bakker, 2001). This proposition is Hypothesis 2a. Supporting the work of Schaufeli et al. (2002), it is further postulated that the adapted version of the UWES used for this study will display sufficient levels of reliability (Hypothesis 2b). It will thus be usable in the South African sport coaching context in a manner that holds scientific integrity.

\section{Position of the job and personal resources in the nomological net}

For the purposes of theoretical classification, the conceptualisation of organisational strengths use and organisational deficit improvement as job resources, as well as 
individual strengths use and individual deficit improvement as personal resources, must be structured within and compared to other similarly postulated constructs in a framework known as the nomological net. The nomological net describes a collection of theoretically overlapping and related concepts, and refers to the interrelationship between such constructs (Westen \& Rosenthal, 2003). From a statistical perspective, it forms part of construct validity.

For the purposes of job resources, the constructs included for relation in the nomological net in this study include opportunities for learning and independence at work. These constructs have been identified as job resources in various studies. Opportunities for learning are the perceptions of the individual of the extent to which their job offers chances for development and learning (Van Veldhoven, Meijman, Broersen \& Fortuin, 2002). Independence at work describes the employee's perception of the extent to which they have autonomy and freedom in determining their own work tasks, activities and actions (Van Veldhoven et al., 2002). In the context of this study, the hypothesis was that a moderate relationship will exist between organisational strengths use, organisational deficit improvement and both opportunities for learning and independence at work, substantiating their classification as job resources (Hypothesis 3a).

From the perspective of personal resources, individual strengths use and individual deficit improvement were considered based on their relation to two distinguished personal resources, namely self-efficacy and self-esteem. Generalised self-efficacy is the belief an individual holds about their innate ability to deal with a broad range of challenges and stressors (Luszczynska, Scholz \& Schwarzer, 2005). It has been described by Judge and Bono (2001, p. 80) as: 'one's fundamental ability to cope, perform and be successful'. Schmitt and Allik (2005, p. 623) describe self-esteem as 'one's overall sense of worthiness as a person'. It is hypothesised that both the individual strengths use and individual deficit improvement will display moderate correlations with these established personal resources (Hypothesis 3b). The relationship with work engagement in the nomological net will be discussed next. This relationship will be tested more rigorously using structural equation modelling.

\section{Structural paths between the strength and deficit-based approach and work engagement}

Studies have found the availability of job resources to be a strong predictor of work engagement (Bakker \& Demerouti, 2007; Xanthopoulou et al., 2009). Considering the fact that organisational strengths use and organisational deficit improvement are defined within the theoretical parameters of job resources, it can reasonably be predicted that these constructs can also predict higher levels of work engagement.

A study by Linley and Harrington (2006) found a direct relation between organisational strengths use and work engagement in an organisation. Possible theoretical contextual explanations for this phenomenon may include the happy-productive worker thesis, a theory that holds that the development of employee strengths will harness positive affect which in turn will kindle high levels of performance through a series of heightened mechanisms of motivation (Cropanzano \& Wright, 2001). Furthermore, the broadenand-build theory of Frederickson (2002) infers that one good experience lays the substance for further advancements towards the optimum development of people. Govindji and Linley (2007) found that organisations that accentuate and develop the strengths of their employees allow for these employees to expand their perspectives, be more happy and, ultimately, more engaged in their work. Luthans and Youssef (2007) have, however, also elaborated on the importance of balancing organisational strengths use with deficit improvement in a realistic approach that seeks the development of the total individual. It is therefore proposed that organisational strengths use is a positive and significant predictor of work engagement (Hypothesis 4a) and that organisational deficit improvement is also a positive and significant predictor of work engagement (Hypothesis $4 b$ ).

Personal resources are a theoretical extension of job resources (Xanthopoulou et al., 2009) and considering the positive relationship that exists between job resources and work engagement, it can reasonably be hypothesised that the personal resources of individual strengths use and individual deficit improvement will also affect work engagement. This is because the individual who possesses individual resources will be more capable of accumulating and utilising job resources effectively, translating such resources into favourable outcomes such as engagement (Hobfoll, 2002; Xanthopoulou et al., 2009). Thus, a structural path between individual strengths use and work engagement is proposed (Hypothesis 5a), as well as a structural path between individual deficit improvement and work engagement (Hypothesis 5b).

\section{Research design}

\section{The research approach}

This study is quantitative in nature, following a crosssectional research approach. A cross-sectional method examines a number of responses of various participants at one point in time (Salkind, 2009). The study is both descriptive and exploratory. Little empirical work exists on the measurement of the strength and deficit-based approach (SDBA) and the possible outcomes that can be generated by following a balanced SDBA.

\section{Research method}

\section{Research participants}

For the purpose of the study, a sample of teachers who fulfil roles as sport coaches at their various schools was used. A representative sample of sport coaches, working at primary and secondary schools across three provinces in South Africa (Gauteng, Free State and North West), was gathered $(N=364)$. The sample comprised a diverse collection of biographical characteristics pertaining to such elements as 
gender, race, level of education and level of sport coached. The sample comprised 225 (61.8\%) female and 139 (38.2\%) male respondents. The predominant home language of participants was Afrikaans, 337 (92.6\%). This was followed by English, spoken by 19 (5.2\%) participants, and Sesotho, spoken by eight $(2.2 \%)$ of the participants. The sample included 355 (97.5\%) White participants and 9 (2.5\%) Black participants. The majority of respondents were in the age groups $20-30$ years $(29.7 \%)$ and $41-50$ years (27.7\%). From an educational perspective, $148(40.7 \%)$ participants were in possession of at least a university degree, whilst $122(33.5 \%)$ held at least a diploma; $88(24.2 \%)$ participants were in possession of a post-graduate university qualification when the study was conducted. Of the total sample, 150 (41.2\%) participants were actively coaching at primary schools and $214(58.8 \%)$ at secondary schools. The level of coaching that most participants had exposure to was school level. Only 91 (25\%) participants had had exposure to coaching at a provincial sport level and only 17 (4.7\%) of participants had coached sport at a national level. The predominant types of sport being coached were athletics (239 participants), netball (146), rugby (106) and hockey (97). However, participants in most cases coached a number of different of sports as opposed to just one sport.

\section{Measuring instrument(s)}

Biographical questionnaire: A biographical questionnaire was utilised to obtain biographical information about the participant sport coaches. Important characteristics that were differentiated included the type of sport coached by the participant, gender, race, age group and professional experience. Participants were also asked to indicate the level of their coaching experience and at what type of school they coached, that is, high school or primary school.

Organisational strengths use, organisational deficit improvement, individual strengths use and individual deficit improvement: The SUDIQ, developed by Els et al. (in press) aims to attain the perceived levels of strengths use and deficit development amongst respondents, on an organisational and an individual level. The measure consists of 43 items, scored on a seven-point frequency scale ranging from 0 (almost never) to 6 (almost always). An example item for strengths use on organisational level is: 'This organisation makes the most of my talents'. Deficit improvement on organisational level is measured by items such as: 'This organisation expects me to improve the things I am not good $a^{\prime}$. A typical strengths use item on individual level is: 'I capitalise on my strengths at work'. On an individual level, deficit improvement is represented by the example item: 'In my job, I work on my shortcomings'. The Cronbach's alpha coefficients that have been determined are 0.96 for organisational strengths use, 0.93 for organisational deficit improvement, 0.92 for individual strengths use and 0.92 for individual deficit improvement (Els et al., in press).

As the participants of this study were predominantly from the educational sector, it was important to distinguish the items contained within the SUDIQ that pertained to the role in which they responded to the scale items. It was imperative that the respondents react to the items in the scale from the capacity of sport coaches, and not as educators or teachers. Therefore, the scale was slightly adapted to foster this understanding and role clarity in answering items. In the case of the SUDIQ, 'This organisation' was replaced by 'The school at which I coach sport'. For example, the item that reads 'In this organisation performance appraisals address my areas for development', was replaced by 'The school at which I coach sport uses performance appraisals to address my areas for development'. This is also the case with regard to the individualised items, for example 'I capitalise on my strengths at work', was replaced by 'I capitalise on my strengths when coaching sport'. To ensure that the scientific integrity of the factorial structure of the measure was maintained, factor structure studies were conducted as part of the statistical analysis process.

Job resources: Two job resources, opportunities for learning and independence at work, were measured through the questionnaire on experience and assessment of work. This instrument, developed in the Netherlands, is best known by its abbreviation VBBA (Van Veldhoven, Meijman, Broersen \& Fortuin, 1997). The VBBA comprises four items for the opportunities for learning dimension and 11 items for the independence at work dimension. Its responses are scored on a four-point frequency rating scale, ranging from 0 (never) to 3 (always). An example of an item for opportunities for learning is 'Do you learn new things in your work as a sport coach?' Independence at work includes the example 'Do you have freedom in carrying out your work activities as a sport coach?' Van Veldhoven et al. (2002) have reported sufficient Cronbach's alpha coefficients for both opportunities for learning $(\alpha=0.84)$, and for independence at work $(\alpha=0.90)$.

Personal resources: Self-efficacy was measured by using the generalised self-efficacy scale (Judge, Locke, Durham \& Kluger, 1998). The instrument comprises eight items, of which four are reversely scored. The generalised self-efficacy scale is scored on a five-point frequency scale, ranging in responses from 1 (strongly disagree) to 5 (strongly agree). An example of an item is: 'I can handle the situations that life brings'. Various studies have confirmed the reliability of the scale, including a Polish $(\alpha=0.90)$ and a South Korean ( $\alpha=0.86$ ) study (Luszczynska et al., 2005). The Rosenberg Self-Esteem Scale was utilised to measure self-esteem. Developed by Rosenberg (1965), the scale comprises a fivepoint frequency scale, ranging in responses from 1 (strongly disagree) to 5 (strongly agree). An example of an item is: 'On the whole I am satisfied with myself'. In a study conducted by Robins, Henden, and Trzesniewski (2001), Cronbach's alpha coefficients varying between 0.88 and 0.90 were found across six separate measurements. During the factor analysis of these two instruments in this particular study, the reversely scored items loaded together on one factor and did not prove to have sufficient reliability. They were therefore discarded for purposes of this study amongst sport coaches. 
Work engagement: The levels of work engagement of participants were measured by the Utrecht Work Engagement Scale (UWES). This measure, developed by Schaufeli et al. (2002), consists of 17 items, scored on a seven-point frequency scale, ranging from 0 (never) to 6 (daily). It is conceptualised through measuring three scales, namely vigour, dedication and absorption (Schaufeli \& Bakker, 2004). A typical item for vigour in the UWES is: 'At my work I feel bursting with energy'. An item for dedication is: 'I find the work that I do full of meaning and purpose'. From an internal consistency perspective, Cronbach's alpha coefficients of the UWES range from 0.68 to 0.91 (Schaufeli et al., 2002). In a separate study performed by Storm and Rothmann (2003), Cronbach's alpha coefficients of 0.78 were found for vigour and 0.89 for dedication in the South African context.

As participants' primary profession was that of educators, it was important to filter their feedback from the perspective of sport coaches. It is imperative that the respondents reacted to the items from the capacity of sport coaches, and not as educators or teachers. Therefore, the scale was slightly adapted to foster this understanding and for ensuring role clarity in answering items. For example, the item 'At my work I feel bursting with energy' was adapted to 'While coaching sport, I feel bursting with energy'. To ensure that the scientific integrity of the factorial structure of the measure was maintained, a factor structure analysis was conducted as part of the statistical analysis process.

\section{Research procedure}

Before engaging the participants for purposes of the study, permission was gained from the headmasters of the various schools that participated in the study. Schools across three geographical areas (provinces) formed part of the study. Participants were all teachers who fulfilled roles as sport coaches at their various schools. Participants were active sport coaches at both primary and secondary schools. An explanatory letter accompanied the questionnaires that were to be completed by respondents, clearly explaining the objective, importance and method of the research. Questionnaires were completed manually by participants. Participation was strictly voluntary (explained to the headmasters and on the questionnaire itself) and anonymous. A set of questionnaires was left at each participating school and a formal engagement with each headmaster allowed the researcher to explain the research procedure very clearly. Questionnaires were left at the schools for between two and three weeks, allowing participants sufficient time for completion at a time of their convenience. After the completed questionnaires had been collected from the schools, the data analysis process began. Schools received a compact, summarised report of the research results presented in written format, for developmental and management purposes. The researcher also expressed his willingness to each headmaster to present the research findings verbally at each school, including practical suggestions. Of the 680 questionnaires distributed amongst the various schools, 364 usable questionnaires were returned (response rate of $53.53 \%)$.

\section{Statistical analysis}

Statistical analysis of the study was done using the statistical programmes SPSS and Mplus 6.1 (Muthén \& Muthén, 2010). Competing measurement models were tested for purposes of factor structure analysis, utilising the Bayesian Information Criterion (BIC) to compare the models. Confirmatory factor analysis was performed with regard to the adapted measuring instruments and their factor structure. Means, skewness and kurtosis of the data were determined through descriptive statistics. By utilising the Cronbach's alpha coefficient, reliability of the instruments was determined. Relationships between variables were investigated by using Pearson product moment correlation coefficients. Statistical significance level was set at $95 \%$ confidence interval ( $p \leq 0.05$ ). A cut-off point of 0.30 was used to determine practical significance of medium effect, with 0.5 indicating practical significance of large effect (Byrne, 2010).

The model investigation process of the research was done using Mplus to specify continuous latent variables. It is assumed by the popular maximum likelihood (ML) estimator that the observed variables are measured on a continuous scale. The covariance matrix represents the input type. The latent variables were created by using individual items as indicators; thus, item parcelling was not applied (Bandalos \& Finney, 2001). The goodness-of-fit of the models was tested by using the traditional $\chi^{2}$ statistic, comparative fit index (CFI), Tucker-Lewis index (TLI), root mean square error of approximation (RMSEA), and standardised root mean square residual (SRMR).

Little consensus exists on the cut-off values for adequate fit; however, conformist guidelines were followed for this study under which fit was considered as satisfactory and sufficient if CFI and TLI values were larger than 0.90 (Byrne, 2010). A RMSEA value of 0.05 or less designated a good fit, and values between 0.08 and 0.05 represented a moderately good model fit (Browne \& Cudeck, 1993). According to $\mathrm{Hu}$ and Bentler (1999), the SRMR value should be smaller than 0.05.

\section{Results}

Factor structures of the adapted SUDIQ and UWES: The measurement model, comprising the latent variables organisational strengths use, organisational deficit improvement, individual strengths use, individual deficit improvement and work engagement, was tested. Individual items were used as indicators. This was done primarily to ensure valid factor structures for the adapted instruments used in the study, namely the SUDIQ and UWES.

Four competing models were tested to gain insight into the factor structures. Firstly, a four-factor structure for the SUDIQ (organisational strengths use, organisational deficit improvement, individual strengths use and individual deficit improvement) and a two-factor structure for engagement (vigour and dedication) were tested. This produced a BIC value of 40216 . Following this, a four-factor structure for the SUDIQ (organisational strengths use, organisational deficit 
improvement, individual strengths use and individual deficit improvement) and a one-factor structure for engagement were tested. This presented a BIC value of 40 210. Subsequently, a two-factor model for the SUDIQ, where the organisational items load on a factor (organisational strengths use and organisational deficit improvement) and the individual items load on a factor (individual strengths use and individual deficit improvement), and a one-factor model for engagement were tested. This model presented a BIC value of 42 496. Lastly, another model was tested where a two-factor structure for the SUDIQ was tested, where all strength-based items load on a factor (organisational strengths use and individual strengths use) and all deficit-based items load on a factor (organisational deficit improvement and individual deficit improvement), together with a one-factor structure for engagement. This model produced a BIC value of 43780 . Based on these results, it can be seen that the lowest BIC value is 40210 (Model 2). Therefore, a four-factor (SUDIQ) and one-factor model (UWES) was established as the best model fit in the study. The goodness-of-fit statistics for this model were $\chi^{2}=2477.02 ; d f=892 ; \mathrm{CFI}=0.97$; TLI $=$ 0.97 and RMSEA $=0.07$. Based on these results, support was found for Hypothesis 1a, but not for Hypothesis 2a.

Positioning of variables in the context of the nomological net: Correlation studies were used to confirm the theoretical positioning of organisational strengths use and organisational deficit improvement as job resources, and individual strengths use and individual deficit improvement as personal resources. This was done to establish both of the postulated job resources and both of the postulated personal resources as such within the framework of the nomological net. Therefore, both in the case of job resources and personal resources, already established theoretical variables had to be incorporated into the study. In the case of job resources, opportunities for learning and independence at work were included. In the case of personal resources, self-efficacy and self-esteem were included. Statistical detail of the positioning of these variables is described in Table 1.

As is evident in Table 1, all the scales are reliable (Cronbach's alpha $\geq 0.70$, Nunnally \& Bernstein, 1994). Support is therefore found for Hypothesis $1 b$ and Hypothesis $2 b$.

Furthermore, and shown in Table 1, positive relationships were found between all job resources measured in the study, including those of organisational strengths use, organisational deficit improvement, opportunities to learn and independence at work. Correlation between organisational strengths use and opportunities to learn was practically significant with a medium effect. The relationship between organisational strengths use and independence at work was also practically significant with a medium effect. In the case of organisational deficit improvement, it was practically significantly related to opportuntities to learn, with a medium effect. There was no practically significant relationship between organisational deficit improvement and independence at work, although the correlation was positive and statistically significant. Therefore, both organisational strengths use and organisational deficit improvement are related to other job resources with the expected strength and significance, supporting Hypothesis $3 a$.

In the case of personal resources, positive correlations were found between all conceptualised resources. Individual strengths use was positively correlated with self-efficacy and self-esteem, in both cases with practical significance of a medium effect. Individual deficit improvement correlated positively and statistically significantly with both selfefficacy and self-esteem, but with no practical significance. It therefore seems that especially individual strengths use correlates with personal resources as expected, supporting Hypothesis $3 b$.

Structural paths between SDBA and work engagement: To test the hypothesised structural model (i.e. the four SUDIQ dimensions predicting work engagement where direct paths were specified between the conceptualised job resources of organisational strengths use, organisational deficit improvement and work engagement, and also between the conceptualised personal resources of individual strengths use, individual deficit improvement and work engagement), structural equation modelling was used. This model was a good fit to the data $\left(\chi^{2}=2477.02 ; d f=892 ; p=0.00 ; \mathrm{CFI}=0.97\right.$; $\mathrm{TLI}=0.97 ; \mathrm{RMSEA}=0.07 ; \mathrm{BIC}=40210)$. The direct structural paths of the model as well as its estimates and significance are reported in Table 2.

As can be seen in Table 2, a positive path was found between organisational strengths use and work engagement $(\beta=0.20$; $p \leq 0.05$ ). Organisational strengths use can thus be seen as a significant predictor of work engagement (confirming

TABLE 1: Descriptive statistics and the correlation matrix $(r)$ of the latent variables.

\begin{tabular}{|c|c|c|c|c|c|c|c|c|c|c|c|}
\hline Variable & M & SD & $\alpha$ & 1 & 2 & 3 & 4 & 5 & 6 & 7 & 8 \\
\hline 1. Organisational strengths use & 4.67 & 1.01 & 0.96 & - & - & - & - & - & - & - & - \\
\hline 2. Organisational deficit improvement & 3.69 & 1.25 & 0.94 & 0.53 & - & - & - & - & - & - & - \\
\hline 3. Opportunities to learn & 2.19 & 0.64 & 0.86 & 0.47 & 0.48 & - & - & - & - & - & - \\
\hline 4. Independence at work & 2.11 & 0.56 & 0.90 & 0.40 & 0.29 & 0.60 & - & - & - & - & - \\
\hline 5. Individual strengths use & 4.79 & 0.91 & 0.93 & 0.48 & 0.31 & 0.43 & 0.48 & - & - & - & - \\
\hline 6. Individual deficit improvement & 4.30 & 1.07 & 0.94 & 0.40 & 0.46 & 0.46 & 0.40 & 0.71 & - & - & - \\
\hline 7. Self-efficacy & 4.42 & 0.64 & 0.77 & 0.06 & 0.03 & 0.09 & 0.17 & 0.30 & 0.19 & - & - \\
\hline 8. Self-esteem & 4.54 & 0.58 & 0.90 & 0.16 & 0.05 & 0.07 & 0.13 & 0.30 & 0.21 & 0.65 & - \\
\hline 9. Work engagement & 4.43 & 1.09 & 0.94 & 0.42 & 0.25 & 0.46 & 0.43 & 0.56 & 0.51 & 0.27 & 0.30 \\
\hline
\end{tabular}


TABLE 2: Estimates $(\beta)$ of the direct structural paths in the standardised model.

\begin{tabular}{|c|c|c|c|c|}
\hline Structural path & Estimates (unstandardised) & SE (unstandardised) & Estimates (standardised) & $p$ \\
\hline Engagement $\rightarrow$ Organisational strengths use & 0.19 & 0.05 & 0.20 & 0.00 \\
\hline Engagement $\rightarrow$ Organisational deficit improvement & -0.06 & 0.05 & -0.07 & 0.20 \\
\hline Engagement $\rightarrow$ Individual strengths use & 0.44 & 0.06 & 0.37 & 0.00 \\
\hline Engagement $\rightarrow$ Individual deficit improvement & 0.18 & 0.06 & 0.21 & 0.00 \\
\hline
\end{tabular}

Engagement $\rightarrow$ Individual deficit improvement

Hypothesis 4a). However, the relationship between organisational deficit improvement and work engagement was not proven significant $(\beta=-0.07 ; p>0.05)$; therefore, organisational deficit improvement cannot be seen as a significant predictor of work engagement (not confirming Hypothesis $4 \mathrm{~b}$ ). A significant and positive path was found between individual strengths use and work engagement $(\beta=0.37 ; p<0.05)$, thereby confirming Hypothesis $5 \mathrm{a}$. This also applied to the relationship between individual deficit improvement and work engagement $(\beta=0.21 ; p<0.05)$, rendering individual deficit improvement a predictor of work engagement and thus confirming Hypothesis 5b. Based on these results, all variables were significant predictors of engagement, except organisational deficit improvement. Individual strengths use was the strongest predictor of work engagement.

\section{Discussion}

The objectives of this study were to test the structural models of adapted versions of both the SUDIQ and the UWES, to relate organisational strengths use and organisational deficit improvement to job resources, and individual strengths use and individual deficit improvement to personal resources, and to prove structural paths between organisational strengths use and organisational deficit improvement, as well as between individual strengths use and individual deficit improvement and work engagement.

The predicted factor structure included a four-factor structure for the SUDIQ and a two-factor structure for the UWES. Adapted versions of these instruments were utilised to ensure practical relevance for specific use in the sport coaching environment. It was therefore important to gain insight into the factorial models of both these measures whilst ensuring their scientific integrity was maintained through validity and reliability tests. It was also important to establish the position of organisational strengths use and organisational deficit improvement in its relation to established job resources, and individual strengths use and individual deficit improvement in relation to established personal resources. This was done to establish the position of these resources in the nomological net. In the case of job resources, opportunities for learning and independence at work were investigated as part of this study. Self-efficacy and self-esteem were the personal resources compared to individual strengths use and individual deficit improvement. Finally, direct structural paths were investigated between the strength and deficit-based approach, on an organisational and an individual level, and work engagement. Positive correlations were predicted, based on findings in literature and proven conceptual frameworks, such as the JD-R model, the happy-productive worker thesis and the broaden-andbuild theory.

The first objective of the study was proving that the SUDIQ would hold a four-factor structure, as reported by Els et al. (in press). This includes organisational strengths use, organisational deficit improvement, individual strengths use and individual deficit improvement. Competing measurement models were utilised to explore this. The hypothesised four-factor structure and competing two-factor structure were tested; differentiation was made between organisational and individual factors as well as between strengths use items and deficit improvement items. The proposed four-factor structure proved to have the best model fit.

The second part of the study's first objective was to prove an adapted version of the SUDIQ would be reliable for use in a sport coaching environment. In this study, the Cronbach's alpha values for organisational strengths use were determined as 0.96 , for organisational deficit improvement as 0.94, for individual strengths use as 0.93 , and for individual deficit improvement as 0.94 . Effectively, all four factors of the adapted SUDIQ were thus proven to be reliable and could be used scientifically in a sport coaching environment. This supported the work done by Els et al. (in press) that found the following Cronbach's alpha values: organisational strengths use $(\alpha=0.96)$, organisational deficit improvement DBA ( $\alpha=0.93)$, individual strengths use $(\alpha=0.94)$, and individual deficit improvement $(\alpha=0.94)$.

The next objective of the study was to prove an adapted UWES would have a two-factor structure. The factor 'absorption' of the traditional three-factor model of the UWES was discarded during this study. Various sources of literature have described absorption as a less acute factor in the concept of work engagement (Schaufeli \& Bakker, 2001). This is because various studies have proven absorption to be a consequence, or result, of work engagement, rather than a direct factor that makes up its composition (Montgomery et al., 2003). Literature currently favours the two-factor conceptualisation of work engagement (Schaufeli \& Bakker, 2001) and subsequently this research proposed a twofactor structure as well. Through competing measurement models, a two-factor model and one-factor model for work engagement were assessed. Ultimately, the one-factor model proved the best fit with sufficient BIC, RMSEA, CFI and TLI values. This is consistent with a large sample study led by Sonnentag (2003) that determined a one-factor structure for work engagement. Storm and Rothmann (2003) have also 
found goodness-of-fit for a one-factor structure for work engagement in a South African sample.

Following the establishment of a one-factor structure for work engagement, it was also important to prove sufficient levels of reliability for the adapted UWES utilised for purposes of this study. In the context of this study, the Cronbach's alpha coefficient was 0.94 , well above the cut-off point proposed by Nunnally and Bernstein (1994) of 0.70. Numerous studies have proven the reliability of the UWES. Cronbach's alpha coefficients have varied between 0.78 and 0.89 across an extended number of samples (Schaufeli et al., 2002). In the South African context, reliabilities have also been proven (e.g. Mostert \& Rathbone, 2001). Through this, it was thus established that the confirmed one-factor structure of the adapted UWES was reliable and could be used effectively in a sport coaching environment.

A further goal of the study was to prove relations between organisational strengths use, organisational deficit improvement and other job resources as found in literature. It was argued that both organisational strengths use and organisational deficit improvement can be postulated as job resources as these constructs allow for the attainment of organisational goals (Bakker \& Demerouti, 2007). It abridges job demands and facilitates an organisational climate that is conducive to the realisation of organisational goals (Xanthopoulou et al., 2009). For comparative purposes, the established job resources of opportunities for learning and independence at work were utilised in this study. Moderate and positive correlations were found between all job resources measured in the study, containing those of organisational strengths use, organisational deficit improvement, opportunities for learning and independence at work. It can therefore still be argued that both organisational strengths use and organisational deficit improvement are job resources, ensuring another objective of the study was met.

Following the confirmation of organisational strengths use and organisational deficit improvement as job resources, it was postulated that individual strengths use and individual deficit improvement are related to personal resources. For the purposes of comparison, self-efficacy and self-esteem were included in this study. Personal resources are individual capitals (Hobfoll, 1989) that assist people in dealing with challenges and stressors, bolstering their capacity to reach personal and work-related goals (Van den Heuvel et al., 2010). It assists people in translating the job resources at their disposal into favourable outcomes (Hobfoll, 2002). In the study moderate and positive correlations were found between individual strengths use with self-efficacy and selfesteem. A positive correlation was found between individual deficit improvement and self-efficacy, as well as between individual deficit improvement and self-esteem. However, neither of these correlations was practically significant. Thus, this study holds that individual strengths use could be regarded as a personal resource; however, it cannot be emphatically proven that individual deficit improvement is a personal resource in relation to the nomological net of other personal resources.
Following the conceptualisation of both the job resources and personal resources, structural paths between organisational strengths use and work engagement had to be established. The prediction was also that structural paths exist between organisational deficit improvement and work engagement. A positive path was found between organisational strengths use and work engagement with estimate values at sufficient levels. It can therefore be stated that organisational strengths use is a predictor of work engagement. This supports the theory of Linley and Harrington (2006), who found a direct correlation between organisational strengths use and work engagement. Cameron et al. (2011) have also proven a relationship between organisational strengths use and positive work-related outcomes. No structural paths between organisational deficit improvement and work engagement could be proven. In the context of this study, organisational deficit improvement was thus not a predictor of work engagement. The objective of confirming structural paths between both organisational strengths use and work engagement, as well as between organisational deficit improvement and work engagement, was thus only partially met.

The next objective of the study was to prove that a structural path exists between individual strengths use and work engagement. Direct structural paths were proven between individual strengths use and work engagement. This supports the work of Govindji and Linley (2007), who found that the capacity to utilise one's strengths is favourable when emerging oneself in the task at hand and achieving personal goals. The following postulation of this study held that individual deficit improvement is a predictor of work engagement. The structural path was proven between these two constructs. From the context of the study it also emerged that individual strengths use is the strongest predictor of work engagement. Thus, an individual who has the capacity to use their strengths is highly likely to experience high levels of work engagement.

\section{Implications for management}

Traditionally, organisations focused their energies on rectifying the deficits and flaws of employees. Buckingham and Clifton (2001) communicated that organisations have spent a great deal of effort on identifying these areas of insufficiency and putting interventions in place to improve these areas. This approach has long been the driving force in the training and development departments of organisations that seek to rectify the areas of deficiency in their enterprises as a means of achieving their organisational objectives (Clifton \& Harter, 2003).

This approach, known as the deficit-based approach, has been very useful in organisational development for a long time. However, a modern perspective requires more from organisations. For totalised and optimum development of the individual to occur, a more balanced approach should be followed in which both the areas of deficits and strengths of employees are accentuated and expanded (Linley et al., 2006; 
Wood et al., 2011). Emphasising the potential and virtues of people enables the achievement of positive outcomes, such as profitability and increased productivity (Cameron et al., 2011). Recognising these areas of strengths is known as the strength-based approach and has the potential to generate a number of favourable outcomes. This premise is held by Luthans and Youssef (2007), who have found a balanced strength and deficit-based approach to be a non-negotiable inclination of the organisation that wants to remain competitive and relevant in a very competitive modern context.

This research has proven that it is critical for management to focus particularly on the accentuation of strengths as a manner of achieving key organisational objectives. A very strong relationship was found between organisational strengths use and work engagement in the sample contained in this study. Organisational strengths use is thus a key predictor of work engagement and can therefore be utilised fruitfully in an organisational context to facilitate an environment conducive to the attainment of organisational goals. This supports the research of Linley and Harrington (2006), who found a direct correlation between organisational strengths use and work engagement. Drawing on this and focusing particularly on the context of sport and sport coaching, it can thus be deducted that the management of schools should place a greater emphasis on the development of sport coaches' strengths, and provide opportunities for such coaches to enhance self-awareness in order to be able to capitalise on their own strengths. Coupling this with the capacity development of coaches to individually improve on their deficits and areas of insufficiency will ensure that favourable work-related outcomes can be met, such as work engagement, the outcome studied in this research.

\section{Implications for the individual}

Within the context of this study, individual strengths use and individual deficit improvement were postulated as personal resources. Personal resources are individual human capitals that assist people to negotiate their challenges and stressors more effectively and enable them to achieve personal and work-related goals (Van den Heuvel et al., 2010).

The study proved significant relationships between personal resources, individual strengths use and individual deficit improvement, and work engagement. Therefore, it can be postulated that the capacity to use strengths and improve deficits is a crucial personal skill for individuals and should therefore be developed as a manner of facilitating optimal human functioning. It was also proved that individual strengths use is the strongest predictor of work engagement of all the variables introduced in the study. Therefore, if an individual has the inherent capacity to utilise their strengths, they will be able to more effectively negotiate job resources and achieve desirable outcomes. This is in line with the work of Van den Heuvel et al. (2010) who stated that personal resources will positively assist the individual in their pursuit of goals.

\section{Limitations of the study and recommendations for future research}

A possible limitation of the study was its cross-sectional design. This ensured a perspective of measurement at a specific time, but did not allow for a longitudinal view of the variables. Considering that the research tests new models, a longitudinal study in the future may be beneficial.

A further relevant limitation was the biographical dynamics of the sample. A major challenge was shifting the mindset of the participants so that they completed the research questionnaire in the capacity of their roles as sport coaches, and not in the mindset of teachers, which is their primary occupation. Various measures were introduced to ensure participants responded from the perspective of their experiences as sport coaches, such as specifying this on the questionnaire and clearly explaining this to the headmasters and participating teachers before the study commenced. By using teachers for purposes of the study, a large sample could be obtained which was beneficial to the statistical analysis process. In South African schools, the predominant number of teachers also coach sport, which made the decision to engage them as participants a logical one. However, a recommendation for future research is to engage professional sport coaches, whose sole occupation is coaching, to assess the hypotheses. This will also prevent disparity that was present in this study (in this same sample, both coaches who informally coach athletes at age group level in schools and national competition level coaches were included).

Homogeneity of the sample was another limitation. From a racial perspective, White respondents were by far in the majority. In South Africa, where true diversity exists, this sample could be described as non-representative of the true population. Value can be gained from a more racially diverse sample group in future studies.

The use of the self-report questionnaires that were used in this study is also a potential stumbling block in research, as it can cause common method variance and may be an altered version of the true perception of participants. However, there are limited means available to counteract this problem (Salkind, 2009). It is suggested, however, that less biased measures are used in future research efforts.

Possible models that include indirect effects could be tested in the future in which personal resources of strengths use and deficit improvement can mediate between organisational strengths use and deficit development and other outcomes such as engagement. It was initially also proposed in this study that the personal resources of individual strengths use and individual deficit improvement will mediate the effect of the job resources, organisational strengths use and organisational deficit improvement, on work engagement. This is consistent with the work of Van den Heuvel et al. (2010), who found that personal resources consist of properties that can translate available job resources into favourable work-related outcomes. This is because personal 
resources are inherent capitals that assist human beings in fostering greater levels of subjective well-being (Peterson \& Seligman, 2004), making them more adept at managing and gaining the most from their available job resources, and thus making the attainment of goals more likely. To establish the individual strengths use and individual deficit improvement as mediators in the context of the study, structure equation modelling was used to investigate the change in structural paths between organisational strengths use, organisational deficit improvement and work engagement. However, the output rendered a 'matrix is not positive definite' message, indicating that the model did not fit the data. No clear mediating properties could therefore be established for the personal resources in this study. However, considering the changeable nature of the variables and the fact that these variables will prove to be dynamic over time, it can reasonably be expected that future studies may reveal individual strengths use and individual deficit improvement as mediators between organisational strengths use, organisational deficit improvement and work engagement.

\section{Conclusion}

In conclusion, the sport and sport coaching industry is in critical need of empirical and substantiated scientific work (Levermore \& Beacom, 2009). This study addressed that need by providing two adapted measures for specific use in the sport and sport coaching environment. Firstly, the SUDIQ was adapted for use in this sector. Through comparing measurement models, a four-factor structure model was found for the scale, comprising organisational strengths use, organisational deficit improvement, individual strengths use and individual deficit improvement. All four of these dimensions were found to be reliable. An adapted version of the UWES was also provided and can be used with scientific integrity in the context of sport coaching in future. In the context of the study, a one-factor structure for work engagement was established. A very high level of reliability was found for the adapted measure, rendering it a useful tool that can be used for scientific study in the sport sector. Organisational strengths use and organisational deficit improvement were related to job resources,and individual strengths use and individual deficit improvement to personal resources. Finally, three of the four dimensions (all except organisational deficit improvement) were significantly and positively related to engagement.

\section{Acknowledgements}

The material in this article is based on work that the National Research Foundation (NRF) supported. Any opinions, findings, conclusions or recommendations in this article are those of the author(s). Therefore, the NRF does not accept any liability for them. In addition, the authors would like to thank Ian Rothmann Jr for his assistance with the statistical analyses.

\section{Competing interests}

The authors declare that they have no financial or personal relationships that may have inappropriately influenced them when they wrote this article.

\section{Authors' contributions}

F.W.S. wrote the manuscript as part of his master's dissertation at the North-West University, Potchefstroom Campus, South Africa. He also assisted in the experimental and project design. K.M. was the project leader and was responsible for the experimental and project design, supervision and assistance in the writing of the article and assisted with the statistical analysis and interpretation of the results.

\section{References}

Arthur, W., Bennett, W., Edens, P.S., \& Bell, S.T. (2003). Effectiveness of training in organizations: A meta-analysis of design and evaluation features. Journal of Applied Psychology, 88(2), 234-245. http://dx.doi.org/10.1037/00219010.88.2.234, PMid:12731707

Bakker, A.B., \& Demerouti, E. (2007). The job demands-resources model: State of the art. Journal of Managerial Psychology, 22, 309-328. http://dx.doi. org/10.1108/02683940710733115

Bakker, A.B., \& Demerouti, E. (2008). Towards a model of work engagement. Career Development International 13(3), 209-223. http://dx.doi. org/10.1108/13620430810870476

Bakker, A.B., Demerouti, E., Taris, T., Schaufeli, W.B., \& Schreurs, P. (2003). A multi-group analysis of the Job Demands-Resources model in four home care organizations. International Journal of Stress Management, 10, 16-38.

Bandalos, D.L., \& Finney, S.J. (2001). Item parcelling issues in structural equation modelling. In G.A. Marcoulides, \& R.E. Schumaker (Eds.), New developments and techniques in structural equation modelling (pp. 269-296). Mahwah, NJ: Lawrence Erlbaum Associates, Inc.

Bouskila-Yam, O., \& Kluger, A.N. (2011). Strength-based performance appraisal and goal setting. Human Resources Management Review, 21(2), 137-147. http:// dx.doi.org/10.1016/j.hrmr.2010.09.001

Brown, J. (2002). Training needs assessment: A must for developing an effective training program. Public Personnel Management, 31(4), 569-578.

Browne, M.W., \& Cudeck, R. (1993). Alternative ways of assessing model fit. In K.A. Bollen, \& J.S. Long (Eds.), Testing structural equation models (pp. 136-162). Newbury Park, CA: Sage.

Buckingham, M., \& Clifton, D.O. (2001). Now, discover your strengths. New York, NY: Free Press.

Byrne, B.M. (2010). Structural equation modelling with AMOS. (2nd edn.). New York NY: Taylor \& Francis Group.

Cameron, K., Mora, C., Leutscher, T., \& Calarco, M. (2011). effects of positive practices on organizational effectiveness. The Journal of Applied Behavioural Science, 47(3), 266-308. http://dx.doi.org/10.1177/0021886310395514

Clifton, D.O., \& Harter, J.K. (2003). Strengths investment. In K.S. Cameron, J.E. Dutton, \& R.E. Quinn (Eds.), Positive organizational scholarship (pp. 111-121). San Francisco, CA: Berrett-Koehler.

Cravens, K.S., Oliver, E.G., \& Stewart, J.S. (2010). Can a positive approach to performance evaluation help accomplish goals? Business Horizons, 53, 269-279. http://dx.doi.org/10.1016/j.bushor.2009.09.005

Cropanzo, R., \& Wright, T.A. (2001). When a 'happy' worker is really a 'productive' worker: A review and further refinement of the happy-productive worker thesis. Practice and Research, 53(3), 182-199.

Csikszentmihalyi, M., \& Rathunde, K. (1993). The measurement of flow in everyday life. Nebraska Symposium on Motivation, 40, 57-97.

Demerouti, E., \& Bakker, A.B. (2011). The job demands-resources model: Challenges for future research. South African Journal of Industrial Psychology 37(2), 1-9.

Demerouti, E., Bakker, A.B., De Jonge, J., Janssen, P.P.M., \& Schaufeli, W.B. (2001). Burnout and engagement at work as a function of demands and control. Burnout and engagement at work as a function of demands and control.
Scandinavian Journal of Work Environment and Health, 27, 279-286. http:// Scandinavian Journal of Work
dx.doi.org/10.5271/sjweh.615

Demerouti, E., Mostert, K., \& Bakker, A.B. (2010). Burnout and work engagement: A thorough investigation of the independency of both constructs. Journal of Occupational Health Psychology, 15(3), 209-222. http://dx.doi.org/10.1037/ Occupational

Els, C., Mostert, K., Van Woerkom, M., Rothmann, S. Jnr, \& Bakker, A.B. (in press). Following a strength-based and deficiency-based approach: The development and psychometric properties of a new scale.

Frederickson, B. (2002). Handbook of Positive Psychology. New York, NY: Oxford University Press.

Gould, D., Guinan, D., Greenleaf, C., \& Chung, Y. (2002). A survey of US Olympic coaches: Variables perceived to have influenced athlete performances and coach effectiveness. The Sport Psychologist, 16, 229-250.

Govindji, R., \& Linley. A. (2007). Strength-use, self-concordance and well-being: Implications for strength coaching and coaching psychologists. International Coaching Psychology Review, 2, 143-153.

Hakanen, J.J., Perhoniemi, R., \& Toppinen-Tanner, S. (2008). Positive gain spirals at work: From job resources to work engagement, personal initiative and workunit innovativeness. Journal of Vocational Behavior, 73(1), 78-91. http://dx.doi. org/10.1016/j.jvb.2008.01.003 
Harter, J.K., Hayes, T.L., \& Schmidt, F.L. (2002). Business-unit level relationships between employee satisfaction, employee engagement and business outcomes: A meta-analysis. Journal of Applied Psychology, 87(2), 268-279. http://dx.doi. A meta-analysis. Journal of Applied
org/10.1037/0021-9010.87.2.268

Hobfoll, S.E. (1989). Conservation of resources: A new attempt at conceptualising strengths. American Psychologist, 44(3), 513-524. http://dx.doi.org/10.1037/0003066X.44.3.513

Hobfoll, S.E. (2002). Social and psychological resources and adaption. Review of General Psychology, 6, 307-324. http://dx.doi.org/10.1037/1089-2680.6.4.307

Hobfoll, S.E., Johnson, R.J., Ennis, N., \& Jackson, A.P. (2003). Resource loss, resource gain, and emotional outcomes among inner city women. Journal of Personality and Social Psychology, 84, 632-663. http://dx.doi.org/10.1037/0022-3514.84.3.632

Hu, L.T., \& Bentler, P.M. (1999). Cut-off criteria for fit indexes in covariance structure analysis: Conventional criteria versus new alternatives. Structural Equation Modeling, 6(1), 1-55. http://dx.doi.org/10.1080/10705519909540118

Judge, T.A., \& Bono, J.E. (2001). Relationship of core self-evaluation traits - selfesteem, generalised self-efficacy, locus of control, and emotional stability with job satisfaction and job performance: A meta-analysis. Journal of Applied Psychology, 86, 80-92. http://dx.doi.org/10.1037/0021-9010.86.1.80, PMid:11302235

Judge, T.A., Locke, E.A., Durham, C.C., \& Kluger, A.N. (1998). Dispositional effects on job and life satisfaction: The role of core evaluations. Journal of Applied Psychology, 83, 17-34. http://dx.doi.org/10.1037/0021-9010.83.1.17, PMid:9494439

Kaiser, R.B., \& White, R.P. (2009). Debunking an unbalanced approach to development. Leadership in Action, 28(5), 9-12.

Keim, M. (2003). National building at play: Sport as a tool for social integration in postapartheid South Africa. Oxford, UK: Meyer \& Meyer Sport.

Levermore, K., \& Beacom, A. (2009). Sport and international development Basingstoke, K: Palgrave McMillan

Linley, A., Willars, J., \& Biswas-Diener, R. (2010). The strengths book: What you can do, love to do, and find it hard to do - and why it matters. Coventry, UK: CAPP Press.

Linley, P.A., \& Harrington, S. (2006). Playing to your strengths. The Psychologist, 19(2), 86-89. http://dx.doi.org/10.1080/17439760500372796

Linley, P.A., Joseph, S., Harrington, S., \& Wood, A.M. (2006). Positive psychology: Past, present, and (possible) future. Journal of Positive Psychology, 1, 3-16.

Linley, P.A., Woolston, L., \& Biswas-Diener, R. (2009). Strength coaching with leaders. International Coaching Psychology Review, 4(1), 20-31.

Luszczynska, A., Scholz, U., \& Schwarzer, R. (2005). The General Self-Efficacy Scale: Multicultural validation studies. The Journal of Psychology, 139(5), 439-457. http://dx.doi.org/10.3200/JRLP.139.5.439-457

Luthans, F., \& Youssef, C.M. (2007). Emerging positive organizational behaviour. Journa of Management, 33(3), 321-349. http://dx.doi.org/10.1177/0149206307300814

Lyle, J. (2002). Sport coaching concepts: A framework for coaches' behaviour. London, UK: Routledge.

Montgomery, A.J., Peeters, M., Schaufeli, W.B., \& Den Ouden, M. (2003). Work-home interference among newspaper managers: Its relationship with burnout and engagement. Anxiety, Stress, \& Coping, 16, 195-211. http://dx.doi.org/10.1080 /10615806.2003.10382973, http://dx.doi.org/10.1080/1061580021000030535

Mostert, K., \& Rathbone, A.D. (2001). Work characteristics, work-home interaction and engagement of employees in the mining industry. Management Dynamics, 16(2), 36-52

Mostert, K., Cronje, S., \& Pienaar, J. (2006). Job resources, work engagement and the mediating role of positive work-home interaction of police officers in the North West Province. Acta Criminologica, 19(3), 64-87.

Mostert, K., Peeters, M., \& Rost, I. (2011). Work-home interference and the relationship with job characteristics and well-being: A South African study among employees in the construction industry. Stress and Health, 27, 238-251. http:// dx.doi.org/10.1002/smi.1374

Muthén, L.K., \& Muthén, B.O. (2010). Mplus user's guide. (6th edn.). Los Angeles, CA: Muthén and Muthén..

Nunnally, J.C., \& Bernstein, I.H. (1994). Psychometric theory. (3rd edn.). New York, NY: McGraw-Hill.

Olusoga, P., Maynard, I., Hays, K., \& Butt, J. (2012). Coaching under pressure: A study of Olympic coaches. Journal of Sport Science, 30(3), 229-239. http://dx.doi.org/1 0.1080/02640414.2011.639384, PMid:22168369

Pearlin, L., \& Schooler, C. (1978). The structure of coping. Journal of Health and Social Behaviour, 19, 2-21. http://dx.doi.org/10.2307/2136319

Peterson, C., \& Seligman, M.E.P. (2004). Character strengths and virtues: A handbook and classification. New York, NY: Oxford University Press.

Peterson, C., Stephens, J.P., Park, N., Lee, F., \& Seligman, M.E.P. (2009). Strength of character and work. In P.A. Linley, S. Harrington, \& N. Garcea (Eds.), Oxford handbook of positive psychology and work (pp. 221-234). Oxford, UK: Oxford University Press. http://dx.doi.org/10.1016/j.matchar.2008.10.005
Rath, T.C. (2002). Measuring the impact of Gallup's strengths-based development program for students. Princeton, NJ: The Gallup Organization.

Robins, R.W., Hendin, H.M., \& Trzesniewski, K.H. (2001). Measuring global selfesteem: Construct validation of a single item measure and the Rosenberg SelfEsteem Scale. Personality and Social Psychology Bulletin, 27, 151-161. http:// dx.doi.org/10.1177/0146167201272002

Rosenberg, M. (1965). Society and the adolescent self-image. Princeton, NJ: Princeton University Press.

Salkind, N.J. (2009). Exploring research. (7th edn.). Englewood Cliffs, NJ: Pearson Prentice.

Schaufeli, W.B., \& Bakker, A.B. (2001). Werk en welbevinden: Naar een positieve benadering in de arbeidsen gezondheidspsychologie [Work and wellbeing: Towards a positive occupational health psychology], Gedrag en Organizatie, 14, 229-253.

Schaufeli, W.B., \& Bakker, A.B. (2004). Job demands, job resources, and their relationship with burnout and engagement: A multi-sample study. Journal of Organizational Behavior, 25, 293-315. http://dx.doi.org/10.1002/job.248

Schaufeli, W.B., Salanova, M., González-Romá, V., \& Bakker, A.B. (2002). The measurement of engagement and burnout: A confirmatory factor analytic approach. Journal of Happiness Studies, 3, 71-92.

Schmitt, D.P., \& Allik, J. (2005). Simultaneous administration of the Rosenberg SelfEsteem Scale in 53 nations: Exploring the universal and culture-specific features of global self-esteem. Journal of Personality and Social Psychology, 89, 623-642. http://dx.doi.org/10.1037/0022-3514.89.4.623

Schutte, N., Toppinen, S., Kalimo, R., \& Schaufeli, W.B. (2000). The factorial validity of the Maslach Burnout Inventory-General Survey across occupational group and nations. Journal of Occupational and Organizational Psychology, 73, 53-66. http://dx.doi.org/10.1348/096317900166877

Seligman, M.E.P. (2002). Authentic happiness. New York, NY: Free Press. PMCid:PMC137417

Seligman, M.E.P., \& Csikszentmihalyi, M. (2000). Positive psychology: An introduction. American Psychologist, 55, 5-14. http://dx.doi.org/10.1037/0003-066X.55.1.5, PMid:11392865

Sienstra, M. (2010). Strength-based development as organisation approach: Will it lead to enhanced task performance and organizational citizenship behaviour and is this relation mediated by subjected well-being? Unpublished master's dissertation, Tilburg University, Tilburg, The Netherlands.

Sonnentag, S. (2003). Recovery, work engagement, and proactive behaviour: A new look at the interface between nonwork and work. Journal of Applied Psychology, 3, 518-528. http://dx.doi.org/10.1037/0021-9010.88.3.518

Stefanyszyn, K. (2007). Norwich union changes focus from competencies to strengths. Strategic HR Review, 7, 10-11.

Storm, K., \& Rothmann, S. (2003). A psychometric analysis of the Utrecht Work Engagement Scale in the South African police service. South African Journal of Industrial Psychology, 29, 62-70.

Swart, K., Bob, U., Knott, B., \& Salie, M. (2011). A sport- and sociocultural legacy beyond 2010: A case study of the football foundation of South Africa. Development Southern Africa, 28(3), 415-428. http://dx.doi.org/10.1080/03768 35X.2011.595997

Van den Heuvel, M., Demerouti, E., Schaufeli, W.B., \& Bakker, A.B. (2010). Persona resources and work engagement in the face of change. In J. Houdmont (Ed.), Occupational health psychology, European perspectives on research, education and practice, Vol. 4 (pp. 124-150). Chichester, UK: John Wiley \& Sons.

Van Veldhoven, M., Meijman, T.F., Broersen, J.P.J., \& Fortuin, R.J. (1997). Handleiding VBBA: Onderzoek naar de beleving van psychosociale arbeidsbelasting en werkstress met behulp van de vragenlijst beleving en beoordeling van de arbeid [Manual VBBA: Research on the experience of psychosocial workload and job stress by means of the Questionnaire on the Experience and Evaluation of Work] Amsterdam, The Netherlands: SKB.

Van Veldhoven, M., Meijman, T.F., Broersen, J.P.J., \& Fortuin, R.J. (2002). Handleiding VBBA. (2nd edn.). Amsterdam, The Netherlands: SKB. PMCid:PMC1222642

Westen, D., \& Rosenthal, R. (2003). Quantifying construct validity: Two simple measures. Journal of Personality and Social Psychology, 84(3), 608-618. http:// dx.doi.org/10.1037/0022-3514.84.3.608, PMid:12635920

Wood, A.M., Linley, P.A., Maltby, J., Kashdan, T.B., \& Hurling, R. (2011). Using personal and psychological strengths lead to increase in well-being over time: A longitudina study and the development of the strengths use questionnaire. Personality and Individual Differences, 50, 15-20. http://dx.doi.org/10.1016/j.paid.2010.08.004

Xanthopoulou, D., Bakker, A.B., Demerouti, E., \& Schaufeli, W.B. (2009). Reciprocal relationship between job resources, personal resources and work engagement Journal of Vocational Behavior, 74, 253-244. http://dx.doi.org/10.1016/j. jvb.2008.11.003 